\title{
Reliability and Validity of the Early Years Physical Activity Questionnaire (EY-PAQ)
}

\author{
Daniel D. Bingham ${ }^{1,2, *}$, Paul J. Collings ${ }^{1}$, Stacy A. Clemes ${ }^{2}$, Silvia Costa ${ }^{3}$, Gillian Santorelli ${ }^{1}$, \\ Paula Griffiths ${ }^{2}$ and Sally E. Barber ${ }^{1}$ \\ 1 Bradford Institute for Health Research, Bradford BD9 6RJ, UK; Paul.Collings@bthft.nhs.uk (P.J.C.); \\ Gillian.Santorelli@bthft.nhs.uk (G.S.); sally.barber@bthft.nhs.uk (S.E.B.) \\ 2 School of Sport, Exercise and Health Sciences, Loughborough University, Leicestershire LE11 3TU, UK; \\ S.A.Clemes@lboro.ac.uk (S.A.C.); P.Griffiths@lboro.ac.uk (P.G.) \\ 3 Centre for Diet and Activity Research (CEDAR), MRC Epidemiology Unit, University of Cambridge, \\ School of Clinical Medicine, Cambridge CB2 0QQ, UK; sc808@medschl.cam.ac.uk \\ * Correspondence: daniel.bingham@bthft.nhs.uk; Tel.: +44-1274-383935
}

Academic Editor: Eling Douwe de Bruin

Received: 8 February 2016; Accepted: 11 May 2016; Published: 26 May 2016

\begin{abstract}
Measuring physical activity (PA) and sedentary time (ST) in young children ( $<5$ years) is complex. Objective measures have high validity but require specialist expertise, are expensive, and can be burdensome for participants. A proxy-report instrument for young children that accurately measures PA and ST is needed. The aim of this study was to assess the reliability and validity of the Early Years Physical Activity Questionnaire (EY-PAQ). In a setting where English and Urdu are the predominant languages spoken by parents of young children, a sample of 196 parents and their young children (mean age $3.2 \pm 0.8$ years) from Bradford, UK took part in the study. A total of 156 (79.6\%) questionnaires were completed in English and 40 (20.4\%) were completed in transliterated Urdu. A total of 109 parents took part in the reliability aspect of the study, which involved completion of the EY-PAQ on two occasions (7.2 days apart; standard deviation $(\mathrm{SD})=1.1)$. All 196 participants took part in the validity aspect which involved comparison of EY-PAQ scores against accelerometry. Validty anaylsis used all data and data falling with specific MVPA and ST boundaries. Reliability was assessed using intra-class correlations (ICC) and validity by Bland-Altman plots and rank correlation coefficients. The test re-test reliability of the EY-PAQ was moderate for ST (ICC $=0.47)$ and fair for moderate-to-vigorous physical activity (MVPA)(ICC $=0.35)$. The EY-PAQ had poor agreement with accelerometer-determined ST (mean difference $=-87.5 \mathrm{~min} \cdot$ day $^{-1}$ ) and good agreement for MVPA (mean difference $=7.1 \mathrm{~min} \cdot \mathrm{day}^{-1}$ ) limits of agreement were wide for all variables. The rank correlation coefficient was non-significant for ST $(\mathrm{rho}=0.19)$ and significant for MVPA (rho $=0.30)$. The EY-PAQ has comparable validity and reliability to other PA self-report tools and is a promising population-based measure of young children's habitual MVPA but not ST. In situations when objective methods are not possible for measurement of young children's MVPA, the EY-PAQ may be a suitable alternative but only if boundaries are applied.
\end{abstract}

Keywords: physical activity; sedentary behaviour; measurement; self-report; preschool; children; accelerometry; ethnicity

\section{Introduction}

The early years (ages $0-5$ ) are vital for establishing healthy lifestyle behaviours including adequate levels of physical activity (PA) and low levels of sedentary time (ST), both of which can have immediate and long-term health impacts [1-3]. In the short term, total PA and moderate to vigorous physical activity (MVPA) both seem to be positively, and ST negatively, associated with multiple 
health outcomes in children (bone health, motor development, cardiovascular risk factors, cognitive development, psycho-social health and healthy adiposity) [3-5]. In the long term, low PA and high ST are key risk factors for the onset of non-communicable diseases later in life (i.e., cardiovascular disease and type II diabetes) [6-10]. These long-term influences may partly be explained by levels of PA and ST tracking over time [11].

Objective monitoring tools, such as accelerometers, are the first choice for field-based measures of PA and ST in young children [12]. Accelerometers can reliably and accurately measure the frequency, intensity and duration of young children's body movement within everyday settings $[13,14]$. Hnatiuk and colleagues [15] reviewed the results of studies measuring PA $(n=40)$ and ST $(n=31)$ in young children using accelerometers, and found that the daily proportion of time spent sedentary ranged from $34 \%$ to $94 \%$, whereas MVPA ranged from $2 \%$ to $41 \%$ of awake time. Although accelerometers are becoming common-place in published research [14], like all methods, accelerometers have limitations, including expense, participant burden, and the level of expertise required to process and analyse data $[12,16-18]$. These factors may preclude large-scale epidemiological studies of young children's (in)activity behaviours, which are particularly required within multi-ethnic and economically diverse populations, as there is a need to better understand health inequalities [19-22].

In 2010, a sub-smaple of the Born in Bradford birth cohort study (BiB-1000) began investigating obesity risk factors for young children living in a multi-ethnic and economically diverse city [23,24]. At the time, there were no available methods deemed appropriate to measure MVPA and ST in this population [24], and an objective measure (such as an accelerometer) was not feasible. For these reasons, a new questionnaire was designed and implemented. A strength of questionnaires over objective measures is the extra contextual information provided about PA and ST (i.e., the activity location and/or type). The new questionnaire generated was the Early Years Physical Activity Questionnaire (EY-PAQ).

The aims of this study were to assess the EY-PAQ's test re-test reliability, and to determine its validity by comparing EY-PAQ data to accelerometry in a sample of young children from a deprived and multi-ethnic population, where English and Urdu are the predominant languages spoken.

\section{Materials and Methods}

\subsection{Participants and Setting}

The study sample consisted of young children aged 18 months to 4 years and their parents who resided in the City of Bradford, UK. Parents were already recruited as part of a pilot cluster randomized controlled trial [25]. Bradford has an approximate population of 500,000 and is the sixth largest metropolitan area in England [26]. The city is also one of the most ethnically diverse and deprived areas in the UK [26]. Ethical approval for the study was granted by the Bradford Teaching Hospitals Foundation Trust ethics committee, and informed consent was obtained from parents.

\subsection{Procedure}

Parents and children attended two appointments with a trained researcher. The first appointment included completion of the EY-PAQ, measurement of children's height and weight, and positioning of the Actigraph GT3X+ tri-axial accelerometer (ActiGraph, Pensacola, FL, USA). Parents were instructed on how to fit the accelerometer to their child, which was attached around the waist over the right hip. They were also asked that their child wore the accelerometer during all waking hours for seven consecutive days. The second appointment took place approximately seven days later. Accelerometers were collected and the same researcher-parent pair completed the EY-PAQ. 


\subsection{Measures}

\subsubsection{The Early Years Physical Activity Questionnaire (EY-PAQ)}

The EY-PAQ is a proxy-reported questionnaire that attempts to quantify levels of habitual MVPA and ST in young children. The questionnaire is available in both English and transliterated Urdu (see supplementary material) [26]. Parents were asked to report the frequency and duration of different MVPA and ST activities in which their child engaged during a typical week in the previous month. The activities for MVPA were: (1) playing actively in the house; (2) playing actively in the garden; (3) walking from place to place; (4) engaging in active play causing sweating and increased breathing; (5) playing in the park or playground, and (6) playing at indoor play facilities. The sedentary activities were: (1) colouring, drawing and craft; (2) sitting playing with toys; (3) watching TV/DVDS; (4) playing a non-active computer game; (5) sitting listening or singing to music; (6) reading or being read to; (7) travelling in a buggy/pushchair; (8) being carried while travelling; (9) travelling in the car; and (10) using public transport. A three-stage process was used to calculate daily minutes of MVPA and ST. First, the duration (reporting options were: 1) up to $15 \mathrm{~min} /$ day; 2) 16-30 min/day; 3) 31-60 $\mathrm{min} /$ day; or 4) free-text for $>60 \mathrm{~min} /$ day) of each activity was multiplied by the frequency that activity occurred. A pragmatic approach was used with regards to the duration component, as parents tend to over-report PA and under-report ST [27], unless free-text responses exceeding $60 \mathrm{~min} /$ day were reported, for the calculation of MVPA, minimum reported durations were used (i.e., $1 \mathrm{~min}, 16 \mathrm{~min}$, or $31 \mathrm{~min}$ ), whereas, for ST, the higher values were used (i.e., $15 \mathrm{~min}, 30 \mathrm{~min}$, and $60 \mathrm{~min}$ ). Second, the calculated duration of each activity was summed and divided by seven in order to estimate daily minutes of MVPA and ST. Third, daily minutes of MVPA and ST were converted to the proportions of waking time spent in these behaviours, by dividing summed minutes in MVPA and ST, respectively, by $840 \mathrm{~min}(\times 100)$. Fourteen hours $(840 \mathrm{~min}$ ) is typical of a waking day in preschool aged children [28], and is in line with sleep diary data that we have collected from similarly aged children from the source population (data not shown). Proportional values were used as the main outcomes because parents completing the EY-PAQ considered the whole day in which an activity may have taken place, whereas accelerometer measured MVPA and ST was only captured during the time the monitor was worn; this rarely reflected entire waking time. Proportions were therefore used to account for disparities in the reference period [29].

Proxy-reported questionnaires often find large variances in PA and ST due to reporting errors [30]. To non-arbitrarily deal with assumed errors, the validity of the questionnaire was examined using two approaches, firstly by using all EY-PAQ data and secondly only data falling within specific MVPA and ST boundaries. These boundaries reflected the range of published ST and MVPA estimates in young children from objective measures [15]. The boundaries for MVPA were $2 \%$ to $41 \%$ and for ST $30 \%$ to $94 \%$ of awake time. The lower boundary for ST was reduced from published value of $34 \%$ to account for non-discretionary sedentary behaviours, such as bathroom or meal times, which accelerometry may have captured but the EY-PAQ did not pose questions about.

\subsubsection{Accelerometry}

The Actigraph GT3X+ (Actigraph Pensacola, FL, USA) is an accurate objective measure that has widely been used to measure young children's PA and ST [17,31-33]. It has been reported to be the favoured device to objectively measure PA in young Bradford children and their mothers [34]. For this study, the accelerometer was set to record data at a sampling rate of 60 Hertz. Raw accelerometer data were downloaded and then transformed into both $5 \mathrm{~s}$ and $15 \mathrm{~s}$ epoch files. Costa [35] found in a British sample of young children (age 2.9 years (SD 0.60)) that both $10 \mathrm{~s}$ and $15 \mathrm{~s}$ epochs significantly underestimated ST. From these findings, a new set of accelerometer cut-points were calibrated and validated using $5 \mathrm{~s}$ epochs [31]. The Costa cut-points were found to be accurate (criterion measure: direct observation [36]) in estimating young childrens' ST but were inaccurate in measuring MVPA. Therefore, we incorporated an alternative cut-point to assess MVPA in this study. The Pate MVPA cut-points were chosen because they have been reported to be the most accurate and appropriate to 
estimate MVPA in young children [37,38]. As ST and MVPA were treated as independent behaviours, the choice of epoch length was set in line with with the procedures of the original calibration studies that developed the ST (Costa: $\leqslant 5$ counts per 5 s) and MVPA (Pate: 420 counts per 15 s) cut-points [13,31], hence processing data with two epoch lengths. The minimum wear-time for inclusion in the analysis was at least $6 \mathrm{~h}$ on any three days, which has been shown to provide reliable activity estimates (ICC $=0.7)$ in the same population of children used in this study [39]. Non-wear time was defined as $\geqslant 10$ min of consecutive zero counts [17]. To calculate the proportion of awake time that each child engaged in behaviours, minutes of accelerometer MVPA and ST were divided by wear time, and multiplied by 100 .

\subsection{Data Analysis}

Descriptive characteristics are presented for all participants and separately for the validity and reliability study participants.

Test/re-test reliability of the EY-PAQ for both MVPA and ST was assessed using a two-way random model intra-class correlation coefficient (ICC $(2,1))$ with $95 \%$ confidence intervals [40]. For the purposes of this study, coefficient values of 0.01 indicated "poor" agreement, 0.01 to 0.20 "slight" agreement, 0.21 to 0.40 "fair" agreement, 0.41 to 0.60 "moderate" agreement, 0.61 to 0.80 "substantial" agreement and 0.81 to 1.00 "almost prefect" agreement [41,42].

For the validity analysis, assessment of whether sex, ethnicity and language modified the relationships between the EY-PAQ and accelerometer MVPA and ST estimates was performed using multiple linear regression analyses. If any demographic variable was found to modify relationships, subsequent analyses were stratified by the influencing variable. All tests were conducted using proportions data, with and without boundaries. Spearman rank correlations (rho) were applied to assess the correlations between the EY-PAQ and accelerometer data. Bland-Altman plots [43] were assembled to assess the agreement between EY-PAQ and accelerometry (before and after applying boundaries). Differences (error) between EY-PAQ and accelerometer estimates of MVPA and ST were calculated (error = EY-PAQ - Actigraph) and plotted against the mean MVPA and ST values of accelerometry and EY-PAQ. The mean difference and direction of systematic error were examined using Pearson error correlations (error $=x$-axis, Actigraph $=y$-axis). Heteroscedasticity was examined using Breusch-Pagan/Cook-Weisberg Tests; where heteroscedasticity was present, heteroscedastic ratio limits of agreement (LOA) were calculated on the log scale $[44,45]$.

All tests (reliability and validity) were performed using proportions (i.e., the $\%$ of awake time in MVPA or ST), but to ease interpretation of the data and enable comparisons with other published questionnaires, proportions were converted back into minutes based upon a waking day of $840 \mathrm{~min}$ [28]. Analyses were conducted using SPSS for windows (version 22) and STATA (version 13), and alpha significance was defined as $p \leqslant 0.05$.

\section{Results}

The demographic characteristics of children are reported in Table 1. In total, 196 children and their parents took part in the validity analysis and 109 took part in the reliability analysis. A breakdown of the number of participants in each of the components of the study, including details of exclusions, is outlined in Figure 1. The mean age was 3.2 years ( $\mathrm{SD} \pm 0.8$ ), $50.5 \%$ were boys and $49 \%$ South Asian (Table 1). Most questionnaires were conducted in English (79.6\%) and with mothers (98\%). There were no significant differences in the sex, ethnicity or age of participants included and those excluded from any aspect of the study. Linear regression models found no significant interactions by sex, ethnicity or language, for the relationships between EY-PAQ and accelerometry; therefore, analyses were not stratified. 
Table 1. Demographic characteristics of children in the validity and reliability analyses of the study.

\begin{tabular}{|c|c|c|c|c|c|c|c|c|}
\hline \multirow{3}{*}{$\begin{array}{l}\text { Demographic and } \\
\text { Outcome Variables }\end{array}$} & \multirow{2}{*}{\multicolumn{2}{|c|}{$\begin{array}{c}\text { All * } \\
n=196\end{array}$}} & \multicolumn{4}{|c|}{ Validity ** } & \multirow{2}{*}{\multicolumn{2}{|c|}{$\begin{array}{c}\text { Reliability } \\
n=104\end{array}$}} \\
\hline & & & \multicolumn{2}{|c|}{$\mathrm{ST}(n=89) * * *$} & \multicolumn{2}{|c|}{$\operatorname{MVPA}(n=102) * * * *$} & & \\
\hline & $n(\%)$ & Mean (SD) & $n(\%)$ & Mean (SD) & $n(\%)$ & Mean (SD) & $n(\%)$ & Mean (SD) \\
\hline \multicolumn{9}{|l|}{ Sex } \\
\hline Boys & $99(50.5)$ & & $47(52.8)$ & & $56(54.9)$ & & $52(48)$ & \\
\hline Girls & $97(49.5)$ & & $42(47.2)$ & & $46(45.1)$ & & $57(53)$ & \\
\hline \multicolumn{9}{|l|}{ Ethnicity } \\
\hline White British & $82(41.8)$ & & $30(33.7)$ & & $37(36.3)$ & & $33(30)$ & \\
\hline South Asian & $96(49)$ & & $52(58.4)$ & & $55(53.9)$ & & $67(62)$ & \\
\hline Other & $18(9.2)$ & & $7(7.9)$ & & $10(9.8)$ & & $9(8)$ & \\
\hline \multicolumn{9}{|l|}{ Age } \\
\hline Years & & $3.2(0.8)$ & & $3.2(0.8)$ & & $3.2(0.8)$ & & $3.3(0.8)$ \\
\hline \multicolumn{9}{|l|}{ Language } \\
\hline English & $156(79.6)$ & & $69(77.5)$ & & $84(82.4)$ & & $82(75)$ & \\
\hline Urdu & $40(20.4)$ & & $20(22.5)$ & & $18(17.6)$ & & $27(25)$ & \\
\hline \multicolumn{9}{|l|}{ EY-PAQ } \\
\hline Proportion estimates (\%) & & & & $47.0(13.6)$ & & $21.2(11)$ & & \\
\hline \multicolumn{9}{|l|}{ Actigraph GT3X+ } \\
\hline Wear time (min per day) & & & & $594.8(100.7)$ & & $582.1(127.3)$ & & \\
\hline Minutes per day & & & & $344.1(88.0)$ & & $118.4(7.5)$ & & \\
\hline Proportion estimates (\%) & & & & $57.5(7.9)$ & & $20.3(7.6)$ & & \\
\hline
\end{tabular}

* Values presented are for validity analysis before the application of boundaries. ${ }^{* *}$ Values presented are for the remaining sample after the application of boundaries. ${ }^{* * *}$ Costa cut-points $(\leqslant 5$ counts per $5 \mathrm{~s}) .{ }^{* * * *}$ Pate cut-points $(\geqslant 420$ counts per $15 \mathrm{~s})$. 


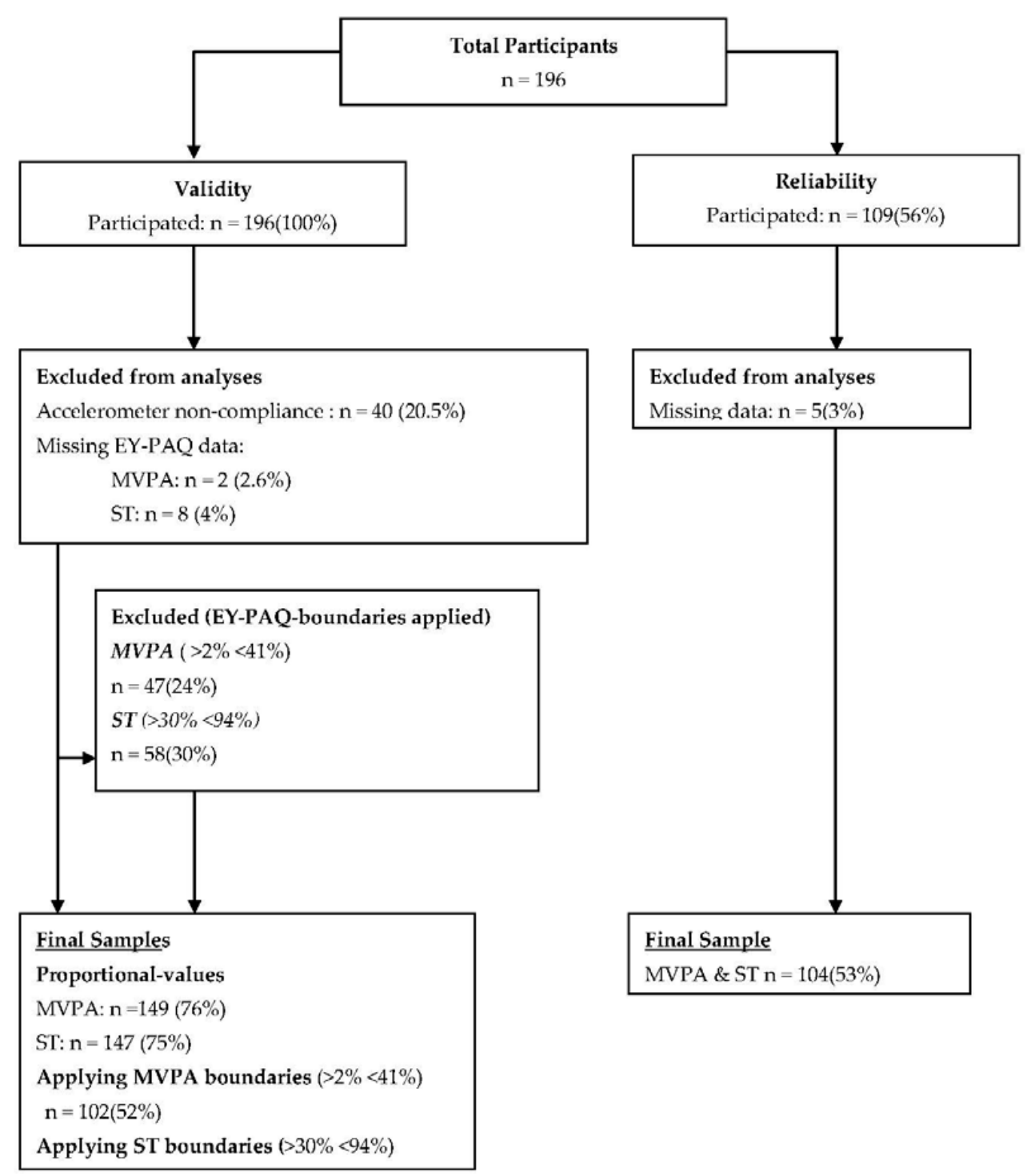

Figure 1. Flow diagram outlining the number of included and excluded participants for the validity and reliability analyses.

\subsection{Reliability}

The average number of days between the completion of the questionnaire at Test 1 and Test 2 was 7.4 days, ranging from five to 12 days.

Table 2 shows the results of the test/re-test reliability analyses. There was fair agreement for test/re-test reliability of MVPA measured by the EY-PAQ (ICC $(2,1)=0.35,95 \%$ CI: $0.17-0.50)$ ). For ST, reliability was moderate $(\operatorname{ICC}(2,1)=0.47,95 \%$ CI: 0.30-0.61)).

Table 2. Intraclass-correlations for moderate to vigorous physical activity (MVPA) and sedentary time (ST) measured by the early years physical activity questionnaire (EY-PAQ).

\begin{tabular}{ccccc}
\hline & \multicolumn{4}{c}{ Reliability } \\
\cline { 2 - 4 } $\begin{array}{c}\text { EY-PAQ Test 1 } \\
\text { vs. Test 2 }\end{array}$ & $\mathbf{n ( \% )}$ & $\begin{array}{c}\text { Mean Daily Difference in } \\
\text { Minutes [95\% CI] }\end{array}$ & ICC (2,1) & $\begin{array}{c}\text { 95\% Confidence } \\
\text { Interval }\end{array}$ \\
\hline MVPA & $104(93.7)$ & $25.5[-23.9,74.8]$ & $0.35 *$ & $0.17-0.50$ \\
ST & $104(93.7)$ & $1.7[-36.5,39.9]$ & $0.47^{*}$ & $0.3-0.61$ \\
\hline
\end{tabular}




\subsection{Validity}

Agreement between MVPA and ST estimated by the EY-PAQ and accelerometry are shown in Figure 2. For MVPA, the mean difference was $7.1 \mathrm{~min} /$ day (LOA: $-185.9 \pm 200.1$ ), and, for ST, the mean difference was $-87.5 \mathrm{~min} /$ day (LOA: $-376.6 \pm 192.7$ ).

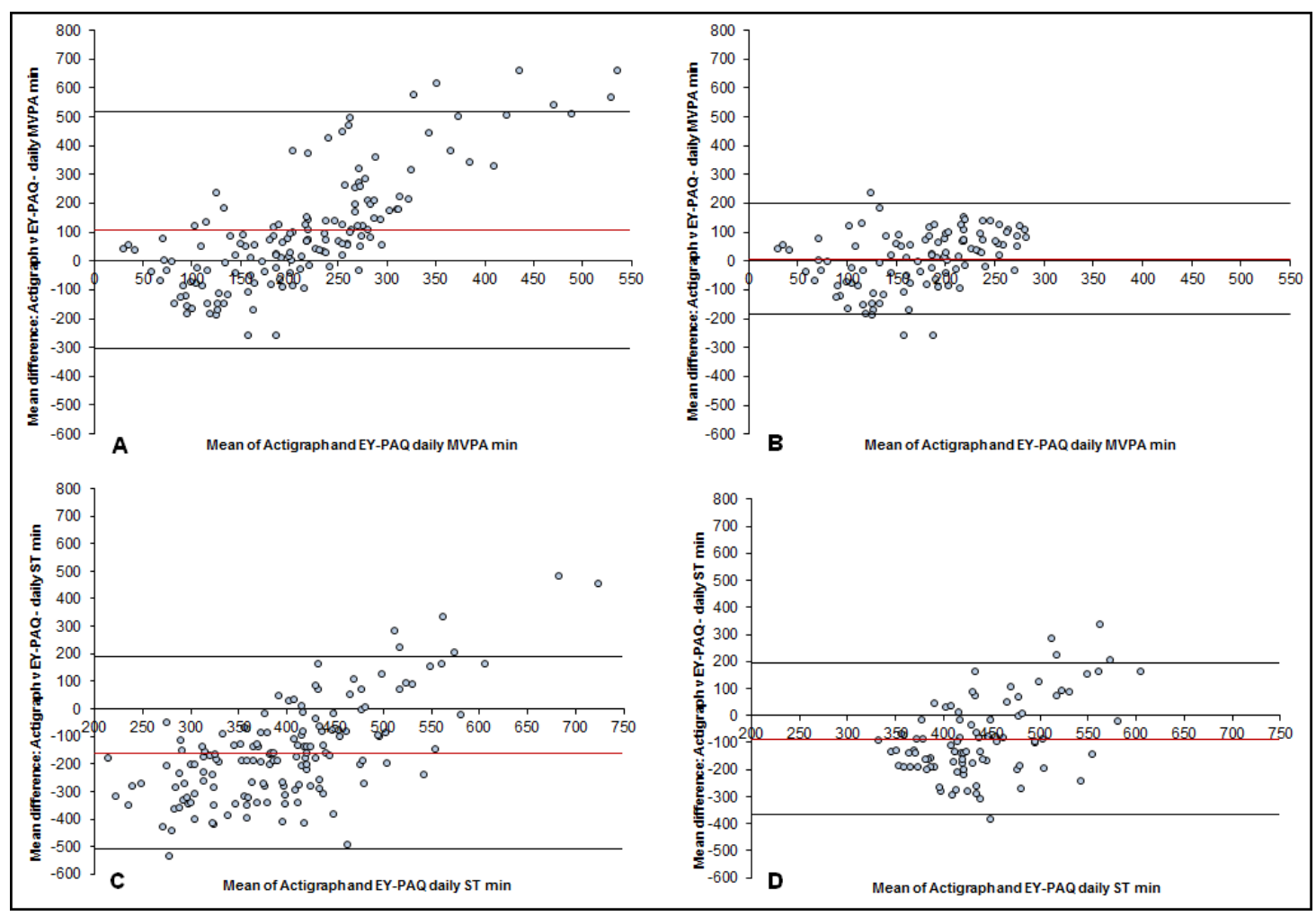

Figure 2. Bland-Altman plots for the difference between time spent in moderate to vigorous physical activity (MVPA) and sedentary time (ST) measured by accelerometry and the Early Years Physical activity questionnaire (EY-PAQ); plotted against the mean average time spent in MVPA and ST measured by the Actigraph and EY-PAQ. (A): MVPA plot for EY-PAQ-MVPA no boundaries applied. Mean difference: 106.3 mins/day; $95 \%$ limits of agreement (LOA): $-303.7,+516.4$. (B): MVPA plot with EY-PAQ-MVPA boundaries applied. Mean difference: $7.1 \mathrm{mins} /$ day; LOA: $-185.9,+200.1$. (C): ST plot for EY-PAQ-ST no boundaries applied. Mean difference: $-160.0 \mathrm{mins} /$ day; LOA: $-509.9,+190.0$. (D): ST plot with EY-PAQ-ST boundaries applied. Mean difference: -87.5 mins/day; LOA: $-376.6,+192.7$.

The only significant correlation between the EY-PAQ and accelerometer was the proportion of time spent in MVPA after applying boundaries (Table 3). Error correlations for all values were found to be statistically significant (Table 3). The significant correlations highlight that systematic error existed. Breusch-Pagan/Cook-Weisburg tests found heteroscedasticity to be present $(p<0.05)$ in the MVPA values and in the ST values. The MVPA mean bias on the ratio scale found MVPA was overestimated by $20 \%(1.20)$ and when the boundary-value was applied this was reduced to an overestimation of $3 \%$ (1.03). The ratio mean bias for ST found that it was overestimated by $72 \%$ (1.72) which was reduced to an overestimation of $26 \%$ (1.26) when the EY-PAQ boundaries were applied. The ratio-limits of agreement were wide for all results (Table 3). 
Table 3. Validity of the early years physical activity questionnaire (EY-PAQ) compared to accelerometry.

\begin{tabular}{|c|c|c|c|c|c|c|c|}
\hline \multirow[b]{2}{*}{ EY-PAQ vs. Accelerometer } & \multicolumn{7}{|c|}{ Validity } \\
\hline & N (\%) & rho & $\begin{array}{l}\text { Mean Daily Difference in } \\
\text { Minutes [95\% CI] }\end{array}$ & $\mathrm{LOA}^{+}$ & Error Correlations (r) & $\begin{array}{l}\text { Heteroskedasicity } \\
p \text {-Value }\end{array}$ & Ratio LOA ${ }^{+}$ \\
\hline MVPA: No boundaries & $149(76.0)$ & 0.03 & $106.3[72.5,140.2]$ & -303.7 to 516.4 & $-0.80 *$ & 0.94 & $1.20(\times / \div 10.6)$ \\
\hline $\begin{array}{l}\text { MVPA: Boundary applied }>2 \% \\
(16.8 \mathrm{~min})<41 \%(344.3 \mathrm{~min}) \#\end{array}$ & $102(52.0)$ & 0.30 * & $7.1[-12.3,26.4]$ & -185.9 to 200.1 & $-0.37 *$ & $<0.01$ & $1.03(\times / \div 5.8)$ \\
\hline ST: No boundaries & $147(75.0)$ & 0.02 & $-160.0[-189.1,-30.9]$ & -509.9 to 190.0 & $-0.67 *$ & $<0.01$ & $1.72(\times / \div 3.6)$ \\
\hline $\begin{array}{c}\text { ST: Boundary applied } \\
>30 \%(252 \mathrm{~min})<94 \%(789.6 \mathrm{~min}) \#\end{array}$ & 89 (45.4) & 0.19 & $-87.5[-117.6,-57.4]$ & -367.6 to 192.7 & $-0.50 *$ & $<0.01$ & $1.26(\times / \div 1.9)$ \\
\hline
\end{tabular}

${ }^{*} p \leqslant 0.05$. \# Hnatiuk et al. [17] boundaries. ${ }^{\dagger}$ Limits of agreement. 


\section{Discussion}

This study examined the reliability and validity of a new activity questionnaire (EY-PAQ) in a sample of young children from a diverse ethnic background where parents spoke either English or Urdu. Findings of the current study show the EY-PAQ has fair reliability for MVPA and moderate reliability for ST. The validity of the EY-PAQ was assessed against accelerometry. A small mean difference and significant correlation was found for MVPA after applying boundaries, leading to the EY-PAQ being an acceptable population method to measure young children's habitual MVPA. For ST, the mean difference was large and the correlation coefficient non-significant. This was true even after applying boundaries to the data, it therefore appears that the EY-PAQ is not a suitable population measure of ST.

The EY-PAQ is a new tool which measures the habitual levels of young children's MVPA and ST. Other similar tools which have been compared to accelerometry are the Preschool-Age Physical Activity Questionnaire (Pre-PAQ) which was developed in Sydney, Australia and measures MVPA, light activity and ST [27], and the Children's Physical Activity Questionnaire (C-PAQ) which was developed in Cambridge, UK and measures MVPA and total PA [44]. The test/re-test reliability of the MVPA component of the EY-PAQ was found to be fair and acceptable [41,42]. Sedentary time had a greater ICC value than MVPA (0.47 and 0.35). In comparison to other published questionnaires, the EY-PAQ's ST ICC was similar to that of the Pre-PAQ's [27] (0.44). The EY-PAQ's MVPA reliability coefficient was lower than the Pre-PAQ's (0.54) and C-PAQ's [44] (0.39). It is perhaps unsurprising that reliability of all questionnaires were low compared to the 'almost perfect' criteria of ICC $=0.8$. Children's PA tends to be highly variable [12], which means levels of MVPA and ST could be very different from one week to the next, thus affecting test/re-test results.

With regards to validity, like the other questionnaires, differences in MVPA and ST were seen between the EY-PAQ and accelerometer. For MVPA, initial results of the EY-PAQ validity assessment revealed larger error values in comparison to the Pre-PAQ and C-PAQ. The EY-PAQ overestimated MVPA by $106.3 \mathrm{~min} /$ day, compared to the Pre-PAQ which overestimated MVPA by $50.1 \mathrm{~min} /$ day, while the CPAQ underestimated MVPA by $-76.5 \mathrm{~min}$. With regards to ST, the EY-PAQ underestimated daily sitting by $160 \mathrm{~min} /$ day, which was a smaller difference to the Pre-PAQ's mean difference of $-208.6 \mathrm{~min} /$ day. However, when the EY-PAQ boundaries were applied differences with accelerometry were reduced to $7.1 \mathrm{~min}$ for MVPA and $-87.5 \mathrm{~min}$ for ST. Like the present study, Corder, van Sluijs [42] also assessed the heteroscedasticity of the C-PAQ and reported the anti-logged ratio limits of agreement. Results showed the C-PAQ at best (depending upon accelerometer cut-points) underestimated MVPA by $32 \%$, which is a greater level of error than the $3 \%$ overestimation witnessed with the EY-PAQ after applying boundaries to the data. Limits of agreement for the EY-PAQ, like the Pre-PAQ and CPAQ, were wide but improved with application of boundaries. Applying the EY-PAQ boundaries also improved the correlation coefficient between the two measures for both MVPA and ST. Before the application of boundaries the EY-PAQ had low, non-significant coefficients (MVPA (rho $=0.03, p \geqslant 0.05$ ) and ST $[r h o=0.02, p \geqslant 0.05]$ ) when compared to the accelerometer. After applying boundaries, the EY-PAQ's validity coefficients increased (MVPA: rho $=0.30$; ST $=0.19$ ). The MVPA coefficient was statistically significant, thus the EY-PAQ successfully ranked young children's MVPA after applying boundaries. The CPAQ also found that it could rank young children's MVPA (rho $=0.42, p \leqslant 0.05$ ). The EY-PAQ's ST coefficient after applying boundaries increased to 0.19 , but was still statistically non-significant.

There are numerous reasons that could explain the differences in the reliability and validity coefficients seen between the EY-PAQ, CPAQ and Pre-PAQ. One reason is that the instruments vary in design and question structure. Another possible reason could be the differences in socio-demographic characteristics of the samples used in the three studies. The Pre-PAQ sample consisted of mainly high socio-economic status, white, English-speaking parents and children from Australia. The samples from both the EY-PAQ and C-PAQ validity studies were located in the UK, but the children in the current study were from communities of high deprivation [23], with a high ethnic mix and two different 
primary languages. Little is known about the sample of the C-PAQ study, other than the sample was from an affluent part of the UK (Cambridgeshire). Future studies should seek to validate multiple questionnaires in the same sample in order to test which of the questionnaires is the most reliable, valid and also feasible. The current study explored interaction by demographic variables such as sex, ethnicity and language on the relationship between the two measures. These variables were not found to impact the association between the EY-PAQ and accelerometry within the present sample.

The error for both MVPA and ST were lowest when mean accelerometer MVPA and ST were highest. This meant that parents were more likely to over or under report MVPA and ST using the EY-PAQ when children's accelerometer-determined levels of MVPA and ST were low. This finding could be explained by the different measurement properties of a proxy-report questionnaire and accelerometer. Dependent upon the placement of the monitor, accelerometry constantly measures movements of the child when worn. However, proxy-report questionnaires are reliant upon what parents observe and remember when completing the questionnaire. Parents will not remember every $15 \mathrm{~s}$ of movement or sedentary time that their young child has engaged in throughout the day, but the accelerometer (in the current study) recorded the child's movement (or lack thereof) every $15 \mathrm{~s}$ (one of the epoch lengths used). Therefore, a difference between the two measurements was foreseeable. Despite the differences between the two types of methods, accelerometers are the most widely used comparison measure in which new self-report tools are validated against [30] Because of the differences, strong coefficients are seldom reported, with most self-reported validity coefficients with accelerometry ranging between 0.25 and 0.41 [30].

In the current study, the inclusion of boundaries informed by data from a recent systematic review [15] narrowed the limits of agreement and greater accuracy was observed. However, it has to be noted this could lead to a possible exclusion of participants, and reduced sample sizes if the EY-PAQ was applied to future population-level studies. In this study, the percentage of participant loss due to the application of boundaries was 23\% $(n=47)$ for MVPA and 30\% $(n=58)$ for ST. Nonetheless, large scale studies using accelerometry also need to factor in participant loss due to the processing of data (e.g., not enough valid wear time). In comparison to large scale studies using accelerometry, the EY-PAQ's participant loss was similar to that of the Healthy Active Preschool Years study (30\%) [46], and less than half of the Millennium Cohort Study (children aged 7-8 years) $(53 \%)$ [47]. The use of the EY-PAQ and accelerometry share the limitation of possible sample size reduction, but the implementation of accelerometry and other objective measures are limited by the burden to participants (e.g., seven days wearing of monitor), level of expertise required to process data and financial costs, all which do not apply to the EY-PAQ. The results of the current study indicate that the EY-PAQ has the smallest limits of agreement after the application of boundaries when measuring MVPA compared to other similar questionnaires [27,44].

It seems that the EY-PAQ is not suitable for measuring young children's ST. The Pre-PAQ also measures ST in young children, and like the EY-PAQ, it was also found to be a weak measure. Reasons for inaccuracy could include that accelerometry would have likely detected most sedentary behaviours including those not measured by the EY-PAQ (e.g., bathroom and meal times). However, the two techniques are also measuring two different behaviours. The EY-PAQ measures the time and frequency that parents report their child sitting down and doing different activities. Accelerometry measures ST by quantifying the absence of movement. Another reason for inaccuracy could be the design of the EY-PAQ's questions. For example, parents rarely used free-text responses to report engagement in sedentary behaviours $\geqslant 60 \mathrm{~min}$, but it is known that, even in this young age group, TV-viewing is prevalent and possibly prolonged. By having a response category with a maximum of 60 min daily, and free-text responses thereafter, we may have unintentionally given parents the impression that we would not have expect higher values, thereby dissuading truthful responses. Future research should bear this in mind and investigate validity and reliability parameters when using different and more suitable comparison measures (e.g., inclinometers [48]) and adding more domains of ST within the EY-PAQ (e.g., time spent sitting while eating). 
A strength of the current study was the relatively large sample of children under the age of five years compared to previous validation studies in young children $[27,44]$. Furthermore, the EY-PAQ sample were from a low socio-economical, ethnically diverse and bi-lingual population; thereby, this studies' novelty adds to the current measurement literature of young children's PA and ST, which is heavily skewed by white English speaking samples [27]. However, results from the current study may not be generalisable to other populations; therefore, additional validity and reliability studies using this new measure in different populations are required. Although a widely used objective field measure, the use of accelerometers as a comparison measure for ST was a limitation; they do not detect posture and only estimate ST through a lack of movement counts. Accelerometry therefore could be argued to be an unsuitable convergent measure for ST [48]. However, there is currently no other objective measure of habitual ST that has been used with children of this age [49]. Finally, (in)activity levels show variation throughout the day in young children [50], meaning that missing data from particular segments of the day (morning, afternoon, or evening) may have influenced our objective data. In this respect, imparting a time-distribution caveat to the accelerometry data may have been worthwhile [51]. Nonetheless, $\geqslant 360 \mathrm{~min}$ of data has commonly been used to define a valid day of accelerometry in young children $[14,32,39,52,53]$, without specifying the pattern of observed data, and our work has shown only small differences in estimated activity levels in the source population with and without specifying that all parts of days must be observed [54].

\section{Conclusions}

The EY-PAQ has acceptable reliability and validity for measuring habitual MVPA of young children from a bi-lingual (English, Urdu), bi-ethnic (White British, South Asian) low socio-economic community. In situations when objective methods are not possible for measurement of MVPA in young children, the EY-PAQ may be a suitable alternative, but only if boundaries are applied. Having such a questionnaire means researchers can explore the early life determinants of MVPA in an ethnically diverse and low socio economic status population at a low cost. Such evidence will be useful for the development of tailored interventions, with better chances to decrease health inequalities in PA and related health outcomes in young children.

Supplementary Materials: The following are available online at http:/ / www.mdpi.com/2075-4663/4/2/30/s1. Appendix A: Early Years Physical Activity Questionnaire English Version; Appendix B: Early Years Physical Activity Questionnaire Urdu Transliteration Version.

Acknowledgments: The involvement of D.D.B., P.J.C., and S.E.B in this publication was through their affiliation with the Healthy Children Healthy Families theme of the National Institute for Health Research (NIHR). Collaboration for Leadership in Applied Health Research and Care (CLAHRC) Yorkshire and Humber. The views expressed in this publication are those of the authors and not necessarily those of the National Health Service, NIHR or Department of Health. The involvement of S.C. in this publication was under the auspices of the Centre for Diet and Activity Research (CEDAR), a UKCRC Public Health Research Centre of Excellence which is funded by the British Heart Foundation, Cancer Research UK, Economic and Social Research Council, Medical Research Council, the National Institute for Health Research, and the Wellcome Trust. The authors would firstly like to thank all of the children and parents who took part in the study. Secondly, the Bradford children's centres and Born in Bradford community staff who were vital during the data collection. Thirdly, we would like to thank Shaheen Akhtar who aided transliteration of the questionnaire.

Author Contributions: D.D.B., S.A.C., and S.E.B. conceived and designed the study. S.E.B. and D.D.B. led the data collection. S.A.C., S.E.B., P.G., and S.C. designed and created the questions which made up the questionnaire (EY-PAQ). G.S. and P.J.C. developed the coding of questionnaire variables. P.J.C. and D.D.B. analyzed the data. All authors read and contributed to the final manuscript, which was written by D.D.B.

Conflicts of Interest: The authors declare no conflict of interest. 


\section{Abbreviations}

The following abbreviations are used in this manuscript:

EY-PAQ Early Years Physical Activity Questionnaire

TPA Total Physical Activity

MVPA Moderate to Vigorous Physical Activity

ST Sedentary Time

BiB Born in Bradford

\section{References}

1. Australian Government Department of Health and Ageing. Physical Activity Recommendations for Children 0-5; Australian Government Department of Health and Ageing: Canberra, Australia, 2009.

2. Reilly, J.; Okely, A.; Almond, L.; Cardon, G.; Prosser, L. Making the Case for UK Physical Activity Guidelines for Early Years: Recommendations and Draft Summary Statements Based on the current Evidence; UK government: London, UK, 2011.

3. Timmons, B.W.; LeBlanc, A.G.; Carson, V.; Gorber, S.C.; Dillman, C.; Janssen, I.; Kho, M.E.; Spence, J.C.; Stearns, J.A.; Tremblay, M.S. Systematic review of physical activity and health in the early years (aged 0-4 years). Appl. Physiol. Nutr. Metab. 2012, 37, 773-792. [CrossRef] [PubMed]

4. Tremblay, M.S.; LeBlanc, A.G.; Kho, M.E.; Saunders, T.J.; Larouche, R.; Colley, R.C.; Goldfield, G.; Gorber, S.C. Systematic review of sedentary behaviour and health indicators in school-aged children and youth. Int. J. Behav. Nutr. Phys. Act. 2011, 8, 1-22. [CrossRef] [PubMed]

5. Ekelund, U.; Hildebrand, M.; Collings, P.J. Physical activity, sedentary time and adiposity during the first two decades of life. Proc. Nutr. Soc. 2014, 73, 319-329. [CrossRef] [PubMed]

6. Lee, I.M.; Shiroma, E.J.; Lobelo, F.; Puska, P.; Blair, S.N.; Katzmarzyk, P.T.; Lancet, W. Effect of physical inactivity on major non-communicable diseases worldwide: An analysis of burden of disease and life expectancy. Lancet 2012, 380, 219-229. [CrossRef]

7. Telama, R.; Yang, X.; Leskinen, E.; Kankaanpaa, A.; Hirvensalo, M.; Tammelin, T.; Viikari, J.S.; Raitakari, O.T. Tracking of physical activity from early childhood through youth into adulthood. Med. Sci. Sports Exerc. 2014, 46, 955-962. [CrossRef] [PubMed]

8. Telama, R.; Yang, X.; Viikari, J.; Valimaki, I.; Wanne, O.; Raitakari, O. Physical activity from childhood to adulthood: A 21-year tracking study. Am. J. Prev. Med. 2005, 28, 267-273. [CrossRef] [PubMed]

9. Wilmot, E.G.; Edwardson, C.L.; Achana, F.A.; Davies, M.J.; Gorely, T.; Gray, L.J.; Khunti, K.; Yates, T.; Biddle, S.J. Sedentary time in adults and the association with diabetes, cardiovascular disease and death: Systematic review and meta-analysis. Diabetologia 2012, 55, 2895-2905. [CrossRef] [PubMed]

10. Biswas, A.; Oh, P.I.; Faulkner, G.E.; Bajaj, R.R.; Silver, M.A.; Mitchell, M.S.; Alter, D.A. Sedentary time and its association with risk for disease incidence, mortality, and hospitalization in adults: A systematic review and meta-analysis. Ann. Intern. Med. 2015, 162, 123-132. [CrossRef] [PubMed]

11. Jones, R.A.; Hinkley, T.; Okely, A.D.; Salmon, J. Tracking Physical Activity and Sedentary Behavior in Childhood A Systematic Review. Am. J. Prev. Med. 2013, 44, 651-658. [CrossRef] [PubMed]

12. Cliff, D.P.; Reilly, J.J.; Okely, A.D. Methodological considerations in using accelerometers to assess habitual physical activity in children aged 0-5 years. J. Sci. Med. Sport 2009, 12, 557-567. [CrossRef] [PubMed]

13. Pate, R.R.; Almeida, M.J.; McIver, K.L.; Pfeiffer, K.A.; Dowda, M. Validation and calibration of an accelerometer in preschool children. Obesity 2006, 14, 2000-2006. [CrossRef] [PubMed]

14. Cain, K.L.; Sallis, J.F.; Conway, T.L.; van Dyck, D.; Calhoon, L. Using accelerometers in youth physical activity studies: A review of methods. J. Phys. Act. Health 2013, 10, 437-450. [PubMed]

15. Hnatiuk, J.A.; Salmon, J.; Hinkley, T.; Okely, A.D.; Trost, S. A review of preschool children's physical activity and sedentary time using objective measures. Am. J. Prev. Med. 2014, 47, 487-497. [CrossRef] [PubMed]

16. Lee, I.-M.; Shiroma, E.J. Using accelerometers to measure physical activity in large-scale epidemiological studies: Issues and challenges. Br. J. Sports Med. 2014, 48, 197-201. [CrossRef] [PubMed]

17. Oliver, M.; Schofield, G.M.; Kolt, G.S. Physical activity in preschoolers: Understanding prevalence and measurement issues. Sports Med. 2007, 37, 1045-1070. [CrossRef] [PubMed] 
18. Fulton, J.E.; Burgeson, C.R.; Perry, G.R.; Sherry, B.; Galuska, D.A.; Alexander, M.P.; Wechsler, H.; Caspersen, C.J. Assessment of Physical Activity and Sedentary Behavior in Preschool-Age Children: Priorities for Research. Pediatr. Exerc. Sci. 2001, 13, 113-126.

19. Taveras, E.M.; Gillman, M.W.; Kleinman, K.; Rich-Edwards, J.W.; Rifas-Shiman, S.L. Racial/ethnic differences in early life risk factors for childhood obesity. Pediatrics 2010, 125. [CrossRef] [PubMed]

20. Misra, A.; Khurana, L.; Vikram, N.K.; Goel, A.; Wasir, J.S. Metabolic syndrome in children: Current issues and South Asian perspective. Nutrition 2007, 23, 895-910. [CrossRef] [PubMed]

21. Bhopal, R. Epidemic of cardiovascular disease in South Asians: Prevention must start in childhood. Br. Med. J. 2002, 324, 625-626. [CrossRef]

22. Bhopal, R. What is the risk of coronary heart disease in South Asians? A review of UK research. J. Public Health Med. 2000, 22, 375-385. [CrossRef] [PubMed]

23. Wright, J.; Small, N.; Raynor, P.; Tuffnell, D.; Bhopal, R.; Cameron, N.; Fairley, L.; Lawlor, D.A.; Parslow, R.; Petherick, E.S.; Pickett, K.E.; Waiblinger, D.; West, J.; Born, G. Cohort profile: The Born in Bradford multi-ethnic family cohort study. Int. J. Epidemiol. 2013, 42, 978-991. [CrossRef] [PubMed]

24. Bryant, M.; Santorelli, G.; Fairley, L.; West, J.; Lawlor, D.A.; Bhopal, R.; Petherick, E.; Sahota, P.; Hill, A.; Cameron, N.; et al. Design and characteristics of a new birth cohort, to study the early origins and ethnic variation of childhood obesity: The BiB1000 study. Longitud. Life Course Stud. 2013, 4, 119-135.

25. Barber, S.E.; Jackson, C.; Akhtar, S.; Bingham, D.D.; Ainsworth, H.; Hewitt, C.; Richardson, G.; Summerbell, C.D.; Pickett, K.E.; Moore, H.J.; et al. "Pre-schoolers in the playground" an outdoor physical activity intervention for children aged 18 months to 4 years old: Study protocol for a pilot cluster randomised controlled trial. Trials 2013, 14, 1-13. [CrossRef] [PubMed]

26. Raynor, P. Born in Bradford, a cohort study of babies born in Bradford, and their parents: Protocol for the recruitment phase. BMC Public Health 2008, 8, 327-339. [PubMed]

27. Dwyer, G.M.; Hardy, L.L.; Peat, J.K.; Baur, L.A. The validity and reliability of a home environment preschool-age physical activity questionnaire (Pre-PAQ). Int. J. Behav. Nutr. Phys. Act. 2011, 8, 86. [CrossRef] [PubMed]

28. Collings, P.J.; Brage, S.; Ridgway, C.L.; Harvey, N.C.; Godfrey, K.M.; Inskip, H.M.; Cooper, C.; Wareham, N.J.; Ekelund, U. Physical activity intensity, sedentary time, and body composition in preschoolers. Am. J. Clin. Nutr. 2013, 97, 1020-1028. [CrossRef] [PubMed]

29. Saint-Maurice, P.F.; Welk, G.J.; Beyler, N.K.; Bartee, R.T.; Heelan, K.A. Calibration of self-report tools for physical activity research: The Physical Activity Questionnaire (PAQ). BMC Public Health 2014, 14, 1-9. [CrossRef] [PubMed]

30. Helmerhorst, H.J.F.; Brage, S.; Warren, J.; Besson, H.; Ekelund, U. A systematic review of reliability and objective criterion-related validity of physical activity questionnaires. Int. J. Behav. Nutr. Phys. Act. 2012, 9. [CrossRef] [PubMed]

31. Costa, S.; Barber, S.E.; Cameron, N.; Clemes, S.A. Calibration and validation of the ActiGraph GT3X+in 2-3 year olds. J. Sci. Med. Sport 2014, 17, 617-622. [CrossRef] [PubMed]

32. Addy, C.L.; Trilk, J.L.; Dowda, M.; Byun, W.; Pate, R.R. Assessing Preschool Children's Physical Activity: How Many Days of Accelerometry Measurement. Pediatr. Exerc. Sci. 2014, 26, 103-109. [CrossRef] [PubMed]

33. Hnatiuk, J.; Ridgers, N.D.; Salmon, J.; Campbell, K.; McCallum, Z.; Hesketh, K. Physical Activity Levels and Patterns of 19-Month-Old Children. Med. Sci. Sports Exerc. 2012, 44, 1715-1720. [CrossRef] [PubMed]

34. Costa, S.; Barber, S.E.; Griffiths, P.L.; Cameron, N.; Clemes, S.A. Qualitative feasibility of using three accelerometers with 2-3-year-old children and both parents. Res. Q. Exerc. Sport 2013, 84, 295-304. [CrossRef] [PubMed]

35. Costa, S. The Measurement of Physical Activity and Sedentary Behaviour in a Sample of 2 to 3 Year Old South Asian and White British Children; Loughborough Univeristy: Leicestershire, UK, 2014.

36. Metcalf, B.S.; Jeffery, A.N.; Hosking, J.; Voss, L.D.; Sattar, N.; Wilkin, T.J. Objectively Measured Physical Activity and Its Association With Adiponectin and Other Novel Metabolic Markers A Longitudinal study in children (EarlyBird 38). Diabetes Care 2009, 32, 468-473. [CrossRef] [PubMed]

37. Trost, S.G.; Fees, B.S.; Haar, S.J.; Murray, A.D.; Crowe, L.K. Identification and validity of accelerometer cut-points for toddlers. Obesity 2012, 20, 2317-2319. [CrossRef] [PubMed] 
38. Gladstone, M.; Lancaster, G.A.; Umar, E.; Nyirenda, M.; Kayira, E.; van den Broek, N.R.; Smyth, R.L. The Malawi Developmental Assessment Tool (MDAT): The Creation, Validation, and Reliability of a Tool to Assess Child Development in Rural African Settings. PLoS Med. 2010, 7, e1000273. [CrossRef] [PubMed]

39. Bingham, D.D.; Costa, S.; Clemes, S.A.; Routen, A.C.; Moore, H.J.; Barber, S.E. Accelerometer data requirements for reliable estimation of habitual physical activity and sedentary time of children during the early years-A worked example following a stepped approach. J. Sports Sci. 2016, 2016, 1-6. [CrossRef] [PubMed]

40. Streiner, D.L.; Norman, G.R. Health Measurement Scales: A Practical Guide to Their Development and Use; OUP Oxford: Oxford, UK, 2008.

41. Landis, J.R.; Koch, G.G. The measurement of observer agreement for categorical data. Biometrics 1977, 33, 159-174. [CrossRef] [PubMed]

42. London, K.C. Q9.10 What Size of Index Indicates "Good Reliability"? Available online: http:/ /www.kcl.ac. uk/ioppn/depts/biostatistics/SAS/faqs9.aspx\#a9_2 (accessed on 2 Februray 2016).

43. Bland, J.M.; Altman, D.G. Statistical methods for assessing agreement between two methods of clinical measurement. Lancet 1986, 1, 307-310. [CrossRef]

44. Corder, K.; van Sluijs, E.M.F.; Wright, A.; Whincup, P.; Wareham, N.J.; Ekelund, U. Is it possible to assess free-living physical activity and energy expenditure in young people by self-report? Am. J. Clin. Nutr. 2009, 89, 862-870. [CrossRef] [PubMed]

45. Atkinson, G.; Nevill, A.M. Statistical methods for assessing measurement error (reliability) in variables relevant to sports medicine. Sports Med. 1998, 26, 217-238. [CrossRef] [PubMed]

46. Hinkley, T.; Salmon, J.; Okely, A.D.; Crawford, D.; Hesketh, K. Preschoolers' physical activity, screen time, and compliance with recommendations. Med. Sci. Sports Exerc. 2012, 44, 458-465. [CrossRef] [PubMed]

47. Lobo, Y.B.; Winsler, A. The effects of a creative dance and movement program on the social competence of head start preschoolers. Soc. Dev. 2006, 15, 501-519. [CrossRef]

48. Hart, T.L.; Ainsworth, B.E.; Tudor-Locke, C. Objective and subjective measures of sedentary behavior and physical activity. Med. Sci. Sports Exerc. 2011, 43, 449-456. [CrossRef] [PubMed]

49. Atkin, A.J.; Gorely, T.; Clemes, S.A.; Yates, T.; Edwardson, C.; Brage, S.; Salmon, J.; Marshall, S.J.; Biddle, S.J. Methods of Measurement in epidemiology: Sedentary Behaviour. Int. J. Epidemiol. 2012, 41, 1460-1471. [CrossRef] [PubMed]

50. Hesketh, K.; McMinn, A.; Ekelund, U.; Sharp, S.; Collings, P.; Harvey, N.; Godfrey, K.; Inskip, H.; Cooper, C.; van Sluijs, E. Objectively measured physical activity in four-year-old British children: A cross-sectional analysis of activity patterns segmented across the day. Int. J. Behav. Nutr. Phys. Act. 2014, 11. [CrossRef] [PubMed]

51. Collings, P.J.; Wijndaele, K.; Corder, K.; Westgate, K.; Ridgway, C.L.; Dunn, V.; Goodyer, I.; Ekelund, U.; Brage, S. Levels and patterns of objectively-measured physical activity volume and intensity distribution in UK adolescents: The ROOTS study. Int. J. Behav. Nutr. Phys. Act. 2014, 11, 23-23. [CrossRef] [PubMed]

52. Hinkley, T.; O'Connell, E.; Okely, A.D.; Crawford, D.; Hesketh, K.; Salmon, J. Assessing volume of accelerometry data for reliability in preschool children. Med. Sci. Sports Exerc. 2012, 44, 2436-2441. [CrossRef] [PubMed]

53. Hislop, J.; Law, J.; Rush, R.; Grainger, A.; Bulley, C.; Reilly, J.J.; Mercer, T. An investigation into the minimum accelerometry wear time for reliable estimates of habitual physical activity and definition of a standard measurement day in pre-school children. Physiol. Meas. 2014, 35, 2213-2228. [CrossRef] [PubMed]

54. Collings, P.J.; Brage, S.; Bingham, D.D.; Costa, S.; West, J.; McEachan, R.R.C.; Wright, J.; Barber, S.E. Bradford Institute for Health Research, Bradford, UK. Unpublished work. 2016.

(C) 2016 by the authors; licensee MDPI, Basel, Switzerland. This article is an open access article distributed under the terms and conditions of the Creative Commons Attribution (CC-BY) license (http://creativecommons.org/licenses/by/4.0/). 